\title{
An Attempt to Explore Effective Pedagogies and their Extensions in Context of Educational Sector of Developing Countries
}

\author{
Neeta Panchmukh \\ MIT School of Education \& \\ Research \\ MIT Art, Design \& Technological \\ University Pune, India
}

\author{
Remica Aggarwal \\ MIT School of Education \& \\ Research \\ MIT Art, Design \& Technological \\ University Pune, India
}

\author{
Smita Kashiramka \\ Department of Management \\ Studies \\ IIT Delhi
}

\begin{abstract}
Successful pedagogies are the backbone of any educational institution. Present article studies the concepts of pedagogy and effective pedagogies in education sector in general as well as with respect to spiritual education pedagogies and its extension .
\end{abstract}

\section{Keywords}

Pedagogies ;Education sector ; Critical Pedagogy

\section{INTRODUCTION}

\subsection{Pedagogy in education and its need}

Classrooms are complex, multi-faceted and demanding places in which to work and successful pedagogies are correspondingly sophisticated. Highly successful pedagogies develop when teachers make outstanding use of their understanding of the research and knowledge-base for teaching in order to support high-quality planning and practice. This gets positively appended by the zeal or passion of the teacher as well as the aspirations of the seekers. This begins with the argument about what constitutes effective teaching, and how a good teacher should behave. This calls for the need of effective pedagogies. Effective pedagogies are known for giving serious considerations to pupil voice ; demonstrating the very best of behaviour, knowledge , understanding and beliefs ; involving clear thinking about short term goals and long term learning outcomes ; involving scaffolding pupil learning; whole class and structured group work ; guided learning and individual activity ; developing higher order thinking and metacognition; developing the skill of assessment ; about bringing diversity in the seekers Research work is arranged as follows. Section 2 define different teaching pedagogies. Section 3 concludes the paper with future directions.

\section{DEFINING DIFFERENT TEACHING PEDAGOGIES [1-6]}

\subsection{Culturally responsive pedagogies /}

\section{Culturally Responsive Teaching}

Culture is central to learning. It plays a role not only in communicating and receiving information, but also in shaping the thinking process of groups and individuals. Culturally Relevant Pedagogy (CRP) is a pedagogical framework coined by[1]. The concept rests on three fundamental pillars of academic achievement, cultural competence and sociopolitical consciousness [1]. The features that characterizes culturally responsive teaching are the positive perspectives on parents and families; communication of high expectations; learning within the context of culture; student-centered instruction ; culturally mediated instruction ;reshaping the curriculum and teacher as facilitator. Some of the criteria considered in culturally relevant pedagogy are as follows ${ }^{2}$ :

- Academic Achievement : Culturally relevant teachers hold high and transparent academic expectations . they have sound knowledge about the content, the learner, the resources available and how to disseminate the knowledge amongst the learners.

- Cultural competence : It makes the teacher as well as the student understands their own cultural background. The teachers as well as the students feel respected and affirmed in their multiple identities, and in return, respect and affirm the multiple identities of others.

- Socio-political consciousness : this criteria encourages the teacher as well as the students to think about and consistently question why things are the way they are and help strengthen their student's mindset and belief that they can be the agents of social change .

\subsection{Effective pedagogy for e-learning in tertiary education 3 / concept of blended learning:}

The brain is a dynamic organ shaped by experiences. Conceptual links are reorganised through active engagement with information in various contexts. Weaving e-learning into existing teaching and learning practices adds more ways for students to be actively and deeply involved with subject area materials . Major benefits include :

- E-learning can improve understanding and encourage deeper learning, if there is careful course design and choice of technology in relation to learning objectives that aim to encourage deeper learning. Students need formative feedback throughout the course. This requires careful structuring and the development of channels and projects encouraging student-student interaction as well as strategic use of teacher time to provide feedback; online tasks, tests, and quizzes are also useful in giving students a picture of their learning progress. 
- Student-student interaction can also be enhanced through careful structuring, creating additional support for learning, and even a "learning community". Participation in discussion groups, etc. is supported by linking it to assessment or tasks and measures that "matter". E-learning is easier for students who are self-managing, which may mean it is easier for mature students. However, recently increasing attention is upon the slow learners and additional course creation, easy to understand slides , video lectures are made available for learners who need them .

\subsection{Critical pedagogy}

Critical Pedagogy known by its myriad names as transformative pedagogy/learning, emancipatory pedagogy, anti-oppressive pedagogy, engaged pedagogy, decolonizing pedagogy, social justice pedagogy, humanizing pedagogy, discomforting pedagogy is in a broad and rudimentary sense a teaching learning methodology that is inspired from the Frankfurt School and ideas of Paulo Friere . Critical Pedagogy is about the critique of existing models of education, it is grounded on social justice, sees education as inherently political and works towards reducing human suffering of various kinds with a focus on those from margins.

While several educationists have now contributed to the idea of critical pedagogy, Freire and Hooks provide for some foundational basis for critical pedagogy in the Americas. Most writings on Critical pedagogy are incomplete if 'The Pedagogy of the Oppressed' by Paulo Friere is not mentioned. Friere [2] problematizes the dehumanizing banking concept of education and puts forth the idea and praxis for problem posing education and the investigation of generative themes for conscientization. Conscientization is about an attitude of awareness, it refers to learning to perceive social, political and economic contradictions and to take action against the oppressive elements of reality.

Some of the notable points about critical pedagogy are : First, critical pedagogy is fundamentally committed to creating an emancipatory culture of schooling that empowers nondominant students. Second, critical pedagogy recognizes how traditional schooling works against the interests of those students who are most vulnerable in society by reproducing class differences and racialized inequality. Third, it makes student strives for agency by first recognizing how they are subjects of history, and then understanding how they can be self-determined to create history. Fourth, critical pedagogy supports a dialectical perspective that recognizes how all analysis must begin with human existence that involves the interactive context between individual and society with a coexistent theory and practice.

\subsubsection{Critical Spiritual Pedagogy [7,8,9]}

- Thus, in an education that embraces the spiritual, we believe that teachers and learners alike must use their spiritual knowledge - regardless of declared religious background - to be critical of the world surrounding us.

- While spirituality has been neglected in the conversations of educational policy that 'works', there is a need to address how spirituality in the classroom can actually be a liberatory practice guiding positive educational change. One of the many strategies for this educational change could be critical spiritual pedagogy. This pedagogy includes:
(1) recognizing a student's unified subjectivities through a pedagogy of integrity as an important strategy to counteract the way students and teachers are often fragmented in the classroom; (2) organizing an interdependent community for the development of humanity in classrooms in the face of Othering social relations based on race, class, gender, sexuality, language .

- Critical spiritual pedagogy can support new teachers to think differently about how they enter the classroom. In teacher education programs, the framework of critical spiritual pedagogy can shape the intentions and broader goals of instruction, without giving a one-size-fits-all best practice policy to first-year teachers.

- Critical spiritual pedagogy places teachers and students as public spiritual intellectuals, with great knowledge and experience on the various social and personal ills people in their community face. This means that both students and teachers must engage in deep reflection on both their own positionalities and actions inside and outside the classroom.

- Critical spiritual pedagogy, as a philosophy in progress, may create more questions than answers for education today. Asking problem-posing questions around the concept of CSP can help guide the development of worldwide liberatory practices by being critical of and working against the fragmented experience of schooling.

\subsubsection{Critical Pedagogies for Dalit children [10-} 19]

Caste based discrimination is an often denied social reality of higher education in India. But, the National Sample Survey (NSS) data (2007-08) for Gross Enrolment Ratio (GER) is indicative of the structural exclusion of students from amongst marginalised social groups. The overall GER in India was 17.31, while GER is the lowest among Scheduled Tribes (ST) at 7.74, followed by Scheduled Castes (SC) at 11.60, Other backward Castes (OBC) (14.80) and others (26.85). A report just released by UNICEF and UNESCO on out of school children in India highlights that Dalit girls have the highest primary school exclusion rate in India. The report also finds that half of the Pre-School age Dalit children are not attending school. The contributing factors were the ingrained social inequalities and poverty among Dalits (scheduled castes); humiliation, harassment and abuse by upper caste teachers towards children from scheduled castes ; child labor ; discrimination in the labor market contributes to low labour market aspirations for Dalit children ; caste based discrimination; blindness to caste in the academic curriculum and the administration of a University ; discrimination on housing and denial of housing to both Dalits and Muslims with Muslims experiencing greater discrimination [14,15]; Suicidal attempts while attaining higher education in India are some of the contributing factors .

More than 17 years later, the situation does not seem to have changed much with [13] putting forth similar experiences of discrimination faced by Dalit and Adivasi students in his article 'Defying the Odds: The Triumphs and Tragedies of Dalit and Adivasi Students in Higher Education'. [13] documents the discrimination faced by 11 interviewees in different institutes and disciplines of higher education from faculty, administration and fellow students. In context of 
Indian society, the writings of Phule and Ambedkar provide much of the ground that articulates from their own experiential reality for a radical humanising anti-caste feminist pedagogy. In Phule-Ambedkar writings, education is seen as an instrument of liberation from the exploitative Hindu caste-patriarchy at the same time as an instrument for the making of a new society that values liberty, equality and fraternity. Despite their enormous contribution to educational thought, their work continues to remain neglected in the Indian educational discourse (Velaskar 2012). Freire, Hooks, Phule and Ambedkar have their own ideas on education and while the core remains aspects of humanization, consciousness raising, social justice and self-actualisation, the content of their thought largely depends on the context. While much of their idea of liberatory education stems from their own experiences of exploitation, domination and humiliation, there are nuances in each of their educational thoughts that can only be formulated from the rootedness of their own lived experience.

The alienation of Phule-Ambedkar's ideas on education is beginning to change. It is rather surprising that such alienation of Ambedkar's work on social transformation was also present in Social Work Education which has social justice as its stated goals. [18] has revived Phule Ambedkarite ideas of education by explaining how Phule and Ambedkar brought together emancipatory non- Vedic materialist traditions of Lokayata, Buddha, Kabir and new western ideas of Thomas Paine, John Dewey, and Karl Marx. The educational philosophy of Phule-Ambedkar challenged the binaries of western modernity/Indian tradition, private castegender/public nation, thereby rethinking modernity and the idea of education. [19] too writes about how new learners in sociology from oppressed communities are 'silenced and sometimes shamed' as a result of their identity based on caste, gender and language in higher education. The acknowledgements of these problems and historical guilt are crucial for guiding new educators to move forward to make higher education democratic, inclusive and liberatory. Both $[18,19]$ have documented pedagogical experiments and in some ways shown the path to a radically humanizing dialogical higher education.

\subsection{Some of the Pedagogies in teaching education}

\subsubsection{Pedagogies in teaching Science [20]:}

One of the main aims of Science Education is the desirable change in attitudes and value teaching. Factors that may be included in this domain -

- creating a more sympathetic stand for scientific knowledge and science education.

- $\quad$ faith in one's abilities

- ability to understand human feelings and respect them

- $\quad$ expressing one's emotions and thoughts creatively

- thinking rationally about individual values and taking decisions accordingly.

- Skills regarding the attitudinal domain cannot be developed through constant advice.

These values are to be assimilated through activities engaged with the society, especially co-students and teachers and learning-teaching activities arranged with a clear-cut aim by teachers.

Project activity is an example for this. The concepts, processes and values become meaningless if the student cannot implement them in daily life.

Similarly, pure scientific principles and concepts divorced from technology, will not have much relevance in daily life. Scientific information is seen to be irrelevant for the student if it is not related to daily life. There are some factors in the application domain--

- observing instances of science concepts in day-to-day life

- use the concepts and skills gained to solve problems related to technology in life.

- avail the benefit of science processes to solve day-today life problems

- ability to evaluate events and developments related to science

- take individual scientific decision on matters of food, health, life style etc. relating science to other subjects

\subsubsection{Pedagogies in teaching economics [21]:}

While teaching economics teachers often makes use of various theories such as constructivism theory, V.A.K learning styles as well as Gardner theory of multiple intelligence for affectively communication and learning. To begin with Teachers who deliver chunks of information that are disconnected will see their students resorting to note learning, since learning is always contextualized. (Muijs and Reynolds, 2005). Further teachers must empower their learners, allowing them to discover and reflect upon their actions, beliefs and experiences. Strategies such as projects, role play, games, case studies all allows for students to construct their own knowledge given their experiences, contexts, surroundings and socioeconomic and cultural backgrounds. Similarly, through V.A.K learning styles, teacher ensure that differentiated learning styles are accommodated. For instance by using a power point presentation we satisfy a visual learner and by playing a game we reach out to a kinesthetics learner. When students are encouraged to discover and use their predominant learning styles in their work, the incidents of poor work and low self-esteem actually decrease. We as teachers tend to teach in our preferred learning style which may not match that of our students. The result is: behavioural and academic issues in the classroom. Various advanced pedagogy techniques such as interactive lectures, print-media , power-point presentation , problem solving based learning, case studies etc. are used for effective delivery of content both from the teacher side as well as from student side.

\subsubsection{Pedagogies in teaching mathematics [22]:}

Teaching of mathematics in the class is concerned with a whole bunch of activities such as computational knowledge of the subject or the selection of mathematical content and communication leading to its understanding and application; adequate and available teaching methods, strategies, and pedagogic resources. Teaching mathematics to the students is a complex activity and therefore the nature and quality of instructional material, the learning environment, the motivation of students are all important to ensure quality in teaching learning of Mathematics 


\section{Objectives of teaching Mathematics in the School}

1. To develop the mathematical skills like speed, accuracy, neatness, brevity, estimation, etc among the students.

2. To develop their logical thinking, reasoning power, analytical thinking, critical thinking.

3. To develop their power of decision-making.

4. To develop the technique of problem solving.

5. To recognize the adequacy or inadequacy of given data in relation to any problem on individual basis.

6. To develop their scientific attitude i.e. to estimate, find and verify results.

7. To develop their ability to analyze, to draw inferences and to generalize from the collected data and evidences.

8. To develop their heuristic attitude and to discover solutions and proofs with their own independent efforts.

9. To develop their mathematical perspective and outlook for observing the realm of nature and society.

\section{Need for Innovative practices in Teaching Mathematics :}

In the modern teaching pedagogy for mathematics, mathematical concepts are also merged with critical thinking, analytical thinking, decision making and problem solving . Such objectives are difficult to be achieved only through verbal and mechanical methods that are usually used in the class of mathematics. As one of the verbal methods of instruction give all importance to speech and texts, to the book and to the teacher who used to be simply satisfied with giving the mathematical rules to pupils and having them memorize it, e.g. The rule of signs and formulas in algebra, students memorize this and remember it. Another verbal method involves explanation. Teachers who use this method assume that the mental structure of the child is same as the adult's.

Usually these stereotype methods though necessary but create a kind of math phobia amongst the students . The Education Commission (1964-66) points out that "In the teaching of Mathematics emphasis should be more on the understanding of basic principles than on the mechanical teaching of mathematical computations".

\subsection{Inclusive Education Pedagogy [23]}

Inclusive means that as teachers "Inclusive means that as teachers, we have the responsibility to seek out all available support (from school authorities, the community, families, children, educational institutions, health services, community leaders, and so on) for finding and teaching ALL children." UNESCO tool Kit

The impact of policies and laws has changed the scenario of education sector significantly. Children from diverse socio economic and cultural back grounds besides children with disabilities are now in regular schools. A typical classroom of a school now will have children from diverse cultures, socio economic background and with human diversities or disabilities. Inclusive education caters to all children from the disadvantaged social groups, linguistic minority gender gifted and talented. One of the important quality you need to develop in inclusive education is being human and responsive to the demand of inclusive education.

Teaching learning process in an inclusive setting classroom dynamics have changed over a period of time. Classrooms now have children from the disadvantaged and different socio economic groups besides children with disabilities. Hence the socio economic conditions and disabilities with the children have implication for their learning therefore as a teacher you need to consider these aspects and understand the child need and accordingly develop inclusive classroom practices for achieving learning outcomes for all children.

Eight Principles of Inclusive teaching learning process are as follows :

- Respecting learners with different abilities and value, diverse talents, different ways of learning and their socio background and personal histories.

- Recognizing and responding to the specific need or additional challenges of learning and makes necessary provision.

- Creating learning friendly environment which facilitates learning for ALL children including children with disabilities.

- Using of flexible and multiple learning approach based on the child's learning pace and style.

- Use of universal design principles to create accessible classes.

- Use of technology for meeting the specific needs of children with disabilities e.g. ICT, aids and appliances and communication technology.

- $\quad$ Reducing barriers within learning environments .

- High expectations for all learners including children with disabilities.

\section{CONCLUSIONS AND FUTURE DIRECTIONS}

There is a robust evidence base which helps to identify the ingredients of outstanding pedagogic practices. However, truly effective practices depend on teachers making active connections between the ideas from research. The most effective successful classroom practices work these ideas together in systematic and sophisticated ways, and the best teachers are active in building relationships between them. Present article deal with exploring various pedagogies in education sector and their extensions in context of developing countries such as India. On quantitative side, barriers or success factors on any of the pedagogy can be accumulated and further their interrelationship could be studied with the help of ISM methodology .

\section{REFERENCES}

[1] Ladson-Billings, G. (1994). The dreamkeepers. San Francisco: Jossey-Bass Publishing Co.

[2] James, M. \& Pollard, A. 2011. TLRP's ten principles for effective pedagogy: rationale, development, evidence, argument and impact, Research Papers in Education, 26(3), 275-328.

[3] Freire, P. 2009. Pedagogy of the Oppressed. New York, NY: The Continuum International Publishing Group Inc. ISBN 978-0-8264-1276-8.

[4] Bodhi, S.R. 2011. Professional Social Work Education in 
India: A Critical View from the Periphery. Indian Journal of Social Work 72, no 2 (2011):289-300.

[5] DfES, 2004. Pedagogy and Practice: Teaching and Learning in Secondary Schools, London, Department for Education and Skills

[6] Ferguson, D.L., Hanreddy, A., \& Draxton, S. 2011. Giving students voice as a strategy for improving teacher practice, London Review of Education, 9(1), 55-70.

[7] Grimmitt, M., (ed.) 2000. Pedagogies of Religious Education: case studies in the research and development of good pedagogic practice in Religious Education, Great Wakering, Essex: McCrimmon .

[8] Dantley, M. E. 2010. Successful leadership in urban schools: Principals and critical spirituality, a new approach to reform. The Journal of Negro Education, 79(3), 214-219.

[9] Ryoo, J.J. ; Crawford , J. Moreno , D. Mclaren , P. Critical Spiritual Pedagogy: reclaiming humanity through a pedagogy of integrity, community, and love , Power and Education, 1(1), 2009, www.wwwords.co.uk/POWER

[10] Chukka, V. 2016. Scholar's Suicide: Discrimination in Higher Education Reflects the Violence of Caste Culture. The Wire.

[11] Khan, K. and Sabarhwal, N.S. 2012. Access and Equity in Higher Education: Aspects of Gender, Caste, Ethnicity, Religion, Occupation and Economic Groups in Rural and Urban Areas During Pre and Post Reform Periods. New Delhi: Indian Institute of Dalit Studies.

[12] Moon, V. and Narke, H. (Editors). 2014. Dr. Babasaheb Ambedkar: Writings and Speeches( Volume III). New Delhi: Dr. Ambedkar Foundation Ministry of Social Justice \& Empowerment, Govt. of India. Pedagogical Practice. Economic and Political Weekly 45, No. 44/45: 88-98.

[13] Singh, A.K. 2013. Defying the Odds: The Triumphs and Tragedies of Dalit and Adivasi Students in Higher Education in Beyond Inclusion: The Practice of Equal
Access in Indian Higher Education Editors Satish Deshpande and Usha Zacharias. New Delhi: Routledge.

[14] Thorat S., Shyamprasad, K.M. and Srivastava, R.K. 2006. Report of the Committee to Enquire into the allegations of Differential Treatment of SC/ST Students in All India Insitute of Medical Science, New Delhi.

[15] Thorat, S. and Paul, A. 2007. The Legacy of Social Exclusion: A Correspondence Study of Job Discrimination in India. Economic and Political Weekly. 42, no 41: 4142-45.

[16] Velaskar, P. and Wankhede, G.G. . 1996. From Old Stigma to New...Exploring the Changing Identity of Urban Educated Dalits. Indian Journal of Social Work 57 (1), 115-134.

[17] Velaskar, P. 2012. Education for Liberation: Ambedkar's Thought and Dalit Women's Perspectives. Contemporary Education Dialogue 9, 2: 245-271.

[18] Rege, S. 2013. Against the Madness of Manu. New Delhi: Narayana.

[19] Sequeira, R. 2014. Why Victims of Custodial Deaths in Maharashtra Only from Minorites? Times of India.

[20] Pedagogy in Science Education KERALA SCERT (2013/15) teacher's guide.

[21] Pedagogic strategies as applied to economics classrooms at senior secondary level . Paper presented at National Seminar on Economics education in Indian schools Organized by Department of Education in Social Sciences and Humanities, National Council of Educational Research and Training, Delhi -16.

[22] Sharma , S.L. , Pedagogy of Mathematics, Innovative Practices in School Mathematics. http://www.ncert.nic.in/pdf_files/Pedagogy_of_Mathema tics_2_.pdf.

[23] Florian, L. \& Linklater, H. 2010. Preparing teachers for inclusive education: using inclusive pedagogy to enhance teaching and learning for all, Cambridge Journal of Education, 40(4), 369- 86. 